\section{Shocking attempted fraud}

Sir: I can confirm that Appendix 1 of Enduring Love is fictional (Mclvor, Psychiatric Bulletin. January 1999, 23, 61; Granville-Grossman, Psychiatric Bulletin, April 1999, 23, 242-243), based on the novel that precedes it rather than the other way round. At the end of a story about rationality, I wanted to produce an extreme example of a highly determined rational prose such as one might find in a psychiatric case study. As I am sure the editors will confirm, in 1997 I submitted the paper to the British Journal of Psychiatry in the name of one of the authors, Dr Wenn. If the monograph had been published, it would have seemed that my novel was based on a genuine case, my characters would have acquired an extra sheen of plausibility and the division between the real and the invented would have become seamless. The authority of the anagrammatic Drs Wenn and Camia would have been enhanced as their names dissolved among the authentic citations in the bibliography. I would have enjoyed thanking the editors for permission to reprint the paper, assuming they granted it.

I was both disappointed and relieved when my submission was respectfully turned down. Had it been otherwise, I am not entirely sure I would have had the courage, or callousness, to proceed. I can also confirm that Ray Dolan the 'friend and hiking companion' is the same as Dr R. Dolan, FRCPsych, Consultant Psychiatrist at the National Hospital for Neurology and Neurosurgery. He is, of course, in no manner implicated in this shocking attempted fraud.

IAN MCEWAN, c/o Jonathan Cape, 20 Vawxhall Bridge Road, London SWIV 2SA

\title{
Corrigendum
}

The Royal College of Psychiatrists Annual Report 1999, p. 13, Irish Division.

The winner of the Trainees' Research Prize was erroneously reported to be Dr Neta Chada. Paragraph 2 should read: 'The Trainees' Research
Day was again a great success with Dr Annette Thampi a worthy winner and the residential meeting took the form of a workshop on supervision with active participation from trainees and consultants." 